\title{
Política y Ciencia Política en América Latina o cuando el poder interfiere en la forma de producir conocimiento en la región. Comentario a Paulo Ravecca, The Politics of Political Science: Re- Writing Latin American Experiences
}

(2019) Routledge Nueva York, 275 pp.

\author{
Jerónimo Ríos Sierra \\ Universidad Complutense de Madrid \\ ORCID ID 0000-0003-3574-0116 \\ jeronimo.rios@ucm.es
}

\section{Cita recomendada:}

Ríos Sierra, J. (2019). Política y Ciencia Política en América Latina o cuando el poder interfiere en la forma de producir conocimiento en la región. Comentario a Paulo Ravecca, The Politics of Political Science: ReWriting Latin American Experiences. Eunomía. Revista en Cultura de la Legalidad, 17, 382-387.

doi: https://doi.org/10.20318/eunomia.2019.5042

A pesar del cientificismo positivista que la ciencia política mal denominada «dura» ha tratado de afianzar desde la revolución conductista de mediados del siglo pasado (Dahl, 1969; Dryzek y Leonard, 1988), lo cierto es que, como sugiere Paulo Ravecca en The Politics of Political Science: Re-Writing Latin American Experiences, recientemente publicado en Routledge, política y ciencia política, en sí, son un binomio indisociable. Esto es, dos elementos necesariamente conectados que, aunque no lo parezca, difícilmente operan como establecimientos estancos (Sodaro, 2006). Otra cosa es que ideología y política se representen expresamente, si bien su esencia como marcos interpretativos de referencia no desaparece en la disciplina.

Asumiendo una impronta post-estructuralista del poder que marca la impronta del trabajo de Ravecca, la relación de este concepto se presenta íntimamente ligada al del conocimiento de manera que la pregunta de partida es la siguiente: ¿puede una ciencia política abordar objetivamente el análisis y la comprensión de la política? 
A modo de feedback loop al más puro estilo eastoniano, el sistema operaría del siguiente modo: la política, entendida como sistema, agente y estructura configura lo político en cuanto a su dimensión epistemológica (Easton, 1965). Es decir, la ontología de la política construye la normatividad de lo político, generando una dependencia recíproca que se retroalimenta. Solo aceptando y normalizando esta dependencia es que la ciencia política puede, per se, consolidar un rigor que a todas luces no puede desproveerse del componente de una subjetividad que resulta inherente a esta ciencia social. Esto es, la ciencia política nunca será algo objetivo. La ciencia política es subjetiva y solo como tal, reconociendo los límites que produce la afectación de cuestiones tales como poder y conocimiento, es que puede incrementar su nivel de rigurosidad. A tal efecto, el argumento de Ravecca incorpora un segundo componente: autorreflexión e interaccionismo. Así, una vez que la política y lo político se imbrican en el ciudadano, es que hay que apostar por una vía emancipatoria que exige, como condición necesaria, de la autorreflexión y la respuesta bottom-up respecto de la cual, una gran responsabilidad recae en la academia.

Si bien, de fondo hay una subjetividad del autor, quien reivindica la misma como vía de (de)construcción del conocimiento, es interesante mostrar cómo su experiencia personal como estudiante de ciencia política en Uruguay le brinda dos elementos que bien validan la hipótesis de partida. De un lado, la reducción de la política a algo estrictamente copado por el sesgo institucionalista; de otro, la ausencia de discursos críticos en su formación académica, especialmente, en relación con la corriente marxista. Esos dos elementos, en cierta medida, invitan a una tercera cuestión, mostrar cómo acontece el orden neoliberal emergente con fuerza tras el fin de la guerra fría y sustituye la particular ciencia política previamente existente. Un proceso en el que, igual que sucediera bajo la experiencia dictatorial del Cono Sur, dogmatiza una particular forma de ver la tríada Estado-Mercado-Sociedad.

Dicho de otro modo, a partir del libro de Ravecca, del cual sería bien interesante extrapolar su hipótesis a una mirada regional mucho más amplia en términos espaciales y longitudinales, es posible apreciar cómo a inicios de los noventa surge en América Latina una nueva ciencia política. A ésta, fallida la experiencia del viejo regionalismo y de la sustitución por importaciones cepalina, unido a la emergencia del Consenso de Washington (Willianson, 1993) y del New Public Management (Osborne y Gaebler, 1992) -en lo que Douglass North (1990) inscribiría en los años del «crecimiento hacia fuera»- le va a generar un impacto y una influencia directa, que marcará su devenir. Es decir, menos Estado, más mercado, privatización, desregulación, externalización, disciplina fiscal y una idea liberal de democracia global permean, especialmente, a partir de dos trabajos que impregnan buena parte de la ciencia política que se produce en el hemisferio occidental: El fin de la historia y el último hombre, de Francis Fukuyama (1992), y El choque de las civilizaciones y la reconfiguración del orden mundial, de Samuel Huntington.

Sin embargo, no solo la democracia construye ciencia política. Existe una ciencia política orgánica, y he ahí el interés del estudio de caso que plantea el libro especialmente con relación a Chile. En el Chile previo a los noventa, no hay democracia, sí aperturismo económico, y a todas luces existe una ciencia política que conecta a la perfección con la dictadura. Pinochet era premiado por Política, que era la revista bandera del Instituto de Ciencia Política, y su hija, Lucía Pinochet, se convirtió en una asidua de las actividades del mismo, como el propio Ravecca presenta en su segundo capítulo

Ello a su vez conecta con uno de los conceptos, a mi juicio, más interesantes del libro: la ciencia política autoritaria. Una ciencia política que, en particular, el autor 
construye a partir de cómo la dictadura de Pinochet modula y se ve retroalimentada desde la politología chilena en busca de una relación mutuamente favorable. Algo, en todo caso, que permite una mirada más amplia, pues sin ir más lejos, el profesor Javier Franzé (2013), hace tan solo unos años, identificaba de manera similar la relación entre ciencia política y régimen político en los casos de España y Portugal. Ello, a través de dos publicaciones de referencia como lo son la Revista de Estudios Políticos y Estudos, respectivamente. Dos publicaciones de clara impronta nacionalista, católica y filofascista. En definitiva, muestras, como en el caso chileno, de una ciencia política dirigida a contener las voces discrepantes, la amenaza de la izquierda, preservar el statu quo y alimentar la noción de una democracia restringida, llámese orgánica, protegida, etc.

Algo particular en lo que enfatiza Ravecca es en cómo la densidad académica cultural hegemónica del pinochetismo se representa en la ciencia política chilena, la cual visibiliza diferentes aspectos de la dictadura, producto de la imbricación entre conocimiento y poder. Fruto de lo anterior, como también pasaba en las dictaduras ibéricas, es posible encontrar la construcción de relatos y narrativas legitimadoras del régimen, que terminan por construir los límites sobre los cuales se vuelca la disciplina. Es decir, no solo restringen la ciencia política a cuestiones tales como políticas públicas, relaciones cívico-militares, aspectos legislativos propios del entonces denominado Derecho Político o elementos culturales, sino que además le vierten un sentido deontológico, estrictamente normativo, moldeado por una impronta ideológica autoritaria sin embargo, no exenta de método.

Dentro de los dos estudios de caso sobre los que discurre el libro, Chile y Uruguay, es posible encontrar igualmente importantes diferencias y he aquí una de ellas. Es decir, cómo por ejemplo, si en Chile es posible observar una relación casi lineal entre el fin de la ciencia política autoritaria y la llegada de la ciencia política liberal -lo que no se reduce a una mera causalidad-, en Uruguay existe una relación sincrónica entre una y otra. Lo anterior, por ejemplo, en tanto que las universidades privadas resultaron mayormente herméticas a la ciencia política oficialista que discurre entre 1973 y 1985. Sea como fuere, dicho hermetismo, ni mucho menos, ha de ser entendido como un espacio de resistencia epistemológica sin más. Todo lo contrario, puede entenderse más bien como la semilla embrionaria de un tipo de conocimiento orientado al mercado y a los fondos internacionales, que incluso se inscribe en la teorización del Estado ya propuesta por la Comisión Trilateral de 1975. Así, más que conferir un sentido teórico y científico estricto a la politología uruguaya, más bien lo que acontece es un proceso de profesionalización, con vistas a un sentido utilitarista, pragmático y consumidor.

Es decir, mientras que en Chile la ciencia política autoritaria es una realidad, para el caso uruguayo no existe como tal, de modo que la dictadura lo que promueve es una suerte de trauma que transformará el tipo de ciencia política a realizar después de la misma. Empero, en ambas situaciones es posible observar un alejamiento, hacia mediados de los ochenta, de las ortodoxias ideológicas, especialmente en el caso chileno. Lo anterior, en tanto que la academia uruguaya tiene una impronta más progresista que aquélla. De hecho, podría decirse que mientras que en Chile hay una ciencia política que anula su antítesis marxista y que construye una forma particular de conocimiento, en el caso uruguayo se restringe a un mero sentido destructivo para con la tradición marxista. A cambio, Ravecca propone que fue en Uruguay en donde la academia, díscola con la dictadura, más contribuyó a la construcción de una realidad polarizada, con independencia del rechazo a la matriz autoritaria, presente en ambos casos. 
Sea como fuere, la ciencia política uruguaya de los setenta será una ciencia política que si bien no es la autoritaria chilena, se distancia críticamente del ensayismo que proponía, entre otros, el profesor de ciencia política en la Facultad de Economía de la Universidad de la República, Carlos Real de Azúa, y cuya relevancia queda patente en el libro. Así, la academia uruguaya de entonces se opondrá frontalmente a la interdisciplinariedad y al pensamiento crítico, sobre la base de una ciencia política que se (auto)propone metodológica y rigurosa, mirando a Estados Unidos, y en clara confrontación a lo que proviene de una Europa. Un viejo continente en el que se abraza mayo del 68 , y en donde la sociología política y la tradición marxista se aúnan en la segunda generación de la Escuela de Frankfurt, destacando nombres como los de Jürgen Habermas, Karl Otto-Apel, Alfred Schmitd u Oskar Negt.

Es de destacar que todo el ejercicio de análisis que se presenta en The Politics of Political Science integra elementos positivistas, a partir de estadística descriptiva, pero igualmente recursos que confieren al texto un importante valor agregado, tanto por la revisión documental que se plantea, como por el recurso de entrevistas en profundidad que enriquece la propuesta metodológica. En cualquier caso, en el capítulo cuatro, titulado "Doing Research, from Fortress to Intimacy", hay que destacar que se recurre a un instrumento exógeno de la ciencia política, tal y como es la autoetnografía.

Aunque pudiera pensarse que es el modo de inscribir el sentido y la experiencia personal de la opresión física y epistemológica del autor en su aproximación al objeto de estudio abordado por el libro, más bien se trata de un esfuerzo por integrar la esfera personal y la experiencia propia a la relación de poder, subjetividad y conocimiento que, como señalaba ab initio, atraviesan sus páginas. Es cierto que, quizá, este capítulo puede entenderse como prescindible, en tanto que hay un capítulo introductorio, un excelente marco teórico que reflexiona sobre los tres pilares recién referidos, una mirada para el caso chileno (capítulo 2) y una mirada para el caso uruguayo (capítulo 3), que nuevamente se integran en un texto concluyente que hace de perfecto corolario. Sin embargo, el recurso de categorizar los capítulos en función de la «distancia» de conocimiento hace que este capítulo más intimista tenga pleno sentido.

Así, hay un capítulo frío (cold), que sería el que tiene que ver con Chile, en donde mayormente hay un trabajo sobre una escala geográfica y un objeto de estudio abordado desde «lo ajeno». Hay un capítulo templado (warm), en el que la subjetividad aparece en forma de relatos y entrevistas, pero también respecto de una escala geográfica en la que se inscribe el autor y que claramente le resulta cercana. Además, en él, por medio de la subjetividad, es que se puede dar cuenta de cómo transita la ciencia política uruguaya a partir de la interacción con la experiencia de la dictadura, del marxismo al liberalismo. Y por último, este capítulo cuatro (hot), en donde la subjetividad del autor es el punto nuclear en medio de esa intersección ubicua para Ravecca, que reposa entre conocimiento y poder. Se trata a todas luces de una reivindicación que, más allá de lo anterior, pone en medio de la discusión de qué manera la vida de las personas se encuentra fuertemente influida por los cambios que acontecen en la política y o político. Tres miradas y tres distancias que terminan por alimentar un debate presentado en la introducción, pero problematizado -en torno a la subjetividad- en el último de sus capítulos.

En cualquier caso, el libro no solo imbrica escalas geográficas y distancias epistemológicas. Igualmente aúna elementos propios de la raíz marxista, con otras tradiciones del pensamiento crítico y en particular, de la teoría queer. De este modo, no solo Marx, e ineludiblemente Nietzsche, sino Foucault, Bourdieu y el postestructuralismo en general se encuentran muy presentes en la manera en la cual se 
discute lo real, lo normativo, lo material y lo simbólico. Elementos en ningún momento estancos, que demandan miradas plurales y transdisciplinares capaces de integrar enfoques y análisis que resuelvan la ecuación de la complejidad. Algo inherente a las teorías radicales de la democracia, en tanto que, cuanto más complejo, más democrático, pues no olvidemos que, en todo caso, para el autoritarismo el recurso fácil es siempre el de simplificar y reducir una noción de poder a una dimensión única, top-down, material y disponible.

Quizá, por ello mismo, conviene escapar de la univocidad interpretativa de la evolución misma de la ciencia política. Como plantea acertadamente Ravecca, no se pasa, por ejemplo, de entender que la politología uruguaya pasó de la tradición marxista, radical y europea a un componente cientificista, objetivo y de impronta estadounidense en aras de dotarse de mayor rigurosidad y de "verdadera» metodología. Lo que propone el autor, y he aquí una idea-fuerza del texto que bien vale la pena rescatar, es que las dictaduras en Chile y Uruguay fueron las que, a modo de trauma, especialmente en el segundo caso, dieron lugar a un proceso subjetivo, en la comunidad académica de referencia, que desemboca en este tránsito disciplinar.

Empero, no todo es producto de las dictaduras. En este proceso bottom-up de escalas geográficas no se puede dejar de lado el auge unipolar de Estados Unidos, el desmoronamiento de la Unión Soviética, el hiperglobalismo y el nuevo regionalismo que llega a América Latina. Asimismo, se hallan inmersos los esfuerzos renovadores por crear una disciplina autónoma en cuanto a conocimiento y que encuentra en el poder su particular núcleo irradiador, influyendo, en suma, en la subjetividad de las academias del Cono Sur. Especialmente, en la «necesidad» de buscar nuevas preguntas, formular renovadas respuestas y articular ambas esferas con un método propio, alejado del Derecho y de la Sociología.

Así y solo así, como sostiene Ravecca, es que se puede escapar de lecturas parsimoniosas y dar cuenta de la particular evolución que experimentan la(s) ciencia(s) política(s) de Chile y Uruguay. Una(s) ciencia(s) política(s) atravesadas por una renovación de la relación entre poder y conocimiento. Un binomio respecto del cual no hay que obviar cómo la subjetividad se encuentra influida por los cambios que acontecen de lo global a lo local y de lo material a lo simbólico, prestando especial atención a la dimensión económica y a la cultural. Cuestiones todas que, como imaginarán, terminan por desembocar en un American way of life que, en todo momento, busca persuadir a la ciencia política como marco de referencia.

Por todo, nos encontramos ante una interesante contribución académica que desde la teoría crítica explora una mirada original, que cuestiona saberes preconcebidos y los pone en la palestra de la revisión y la resignificación, de modo que queda patente cómo la política y el poder modulan lo político y lo politológico. Ello se lleva a cabo desde un planteamiento en el que el autor apela de forma metafórica a un continuum de temperaturas (caliente/templado/frío) con las que se explora, desde diferentes recursos investigativos, la forma particular en la que la subjetividad responde y se integra en los factores que, desde el poder, modulan dicho conocimiento.

En conclusión, lo objetivo no existe como tal y lejos de incurrir en puritanismos academicistas, de lo que se trata es de normalizar la impronta subjetiva sobre la base del recurso ético, sin entender por ello la rigurosidad disciplinar como excluyente a trascender del supuesto rigor de la ciencia política «dura». El poder, y más en la ciencia política, es un elemento cuasi indisociable de aquélla, el cual, como proponía Lukes (1974), en todo momento hay que identificar y abordar como objeto de estudio. Especialmente, por ser un marco interpretativo que, por su relevancia, cuando resulta 
pasado por alto es capaz de desdibujar y alterar el sentido de las preguntas y las respuestas que, en sí, dan significado mismo a la ciencia política. Una ciencia política ha de entenderse como construcción de conocimiento en sí misma pero sin desconocer que cuando resulta dirigida por fuerzas motoras del poder políticoeconómico-cultural, corre el riesgo de acotar las fronteras del debate académico, su sentido, su alcance y hasta su orientación. Algo, inexorable de un conocimiento en continua disputa, fácilmente subsumible en ejes opresivos y hegemónicos, pero donde en cualquier caso, el campo de batalla sigue abierto.

\section{Bibliografía}

Crozier, M., Huntington, S. y Watanuki, J. (1975). The Crisis of Democracy: On the Governability of Democracies. Nueva York: Trilateral Commission - Rockefeller Foundation.

Dahl, R. (1969). The behavioral approach in political science: Epitaph for a monument to a successful protest. En H. Eulau. Behavioralims in political science (pp. 6892). Nueva York: Atherton Press.

Dryzek, J., y Leonard, S. (1988). History and Discipline in Political Science. The American Political Science Review, 82(4), pp. 1245-1260.

Easton, D. (1965). A Systems Analysis of Political Life. Chicago: University of Chicago Press.

Franzé, J. (2013). Hermandad y Guerra. Los conceptos de España y Portugal en la Revista Estudos y en la Revista de Estudios Políticos (1941-1950). Historia y política: ideas, procesos y movimientos sociales, 30, pp. 89-116.

Fukuyama, F. (1992). The End of History and the Last Man. Nueva York: Free Press.

Huntington, S. (1996). The Clash of Civilizations and the Remaking of World Order. Nueva York: Simon \& Schuster.

Lukes, S. (1986). Power: A Radical View. Londres: Red Globe Press.

North, D. (1990). Institutions, Institutional Change and Performance. Cambridge: Cambridge University Press.

Osborne, D. y Gaebler, T. (1992). Reinventing Government. How the Entrepreneurial Spirit is Transforming the Public Sector. Nueva York: Penguin Press.

Sodaro, M. (2006). Política y ciencia política: una introducción. Madrid: McGraw-Hill.

Williamson, J. (1993). Democracy and the Washington consensus. World Development, 21(8), pp. 1239-1336. 